\title{
Enhanced spin-valve giant magneto-resistance in non-exchange biased sandwich films
}

M. Mao, C. Cerjan, B. Law, F. Grabner, L. Miloslavsky, C. Chien

U.S. Department of Energy

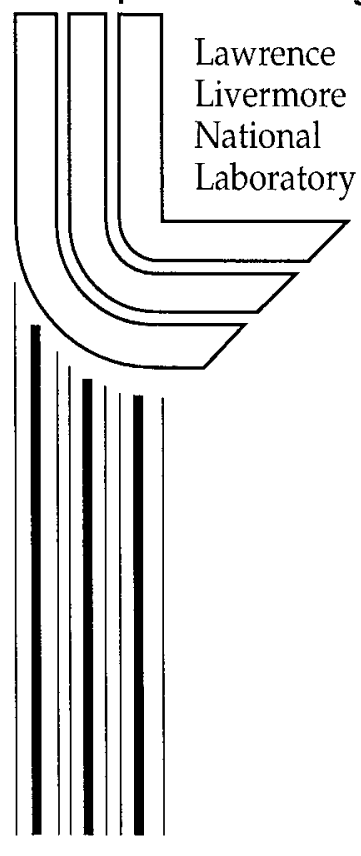

This article was submitted to

Intermag 2000, Toronto, Canada, April 9-13, 2000

\section{February 17, 2000}




\section{DISCLAIMER}

This document was prepared as an account of work sponsored by an agency of the United States Guvernment. Neither the United States Government nor the University of California nor any of their employees, makes any warranty, express or implied, or assumes any legal liability or responsibility for the accuracy, completeness, or usefulness of any information, apparatus, product, or process disclosed, or represents that its use would not infringe privately owned rights. Reference herein to any specific commercial product, process, or service by trade name, trademark, manufacturer, or otherwise, does not necessarily constitute or imply its endorsement, recommendation, or favoring by the United States Government or the University of California. The views and opinions of authors expressed herein do not necessarily state or reflect those of the United States Government or the University of California, and shall not be used for advertising or product endorsement purposes.

This is a preprint of a paper intended for publication in a journal or proceedings. Since changes may be made before publication, this preprint is made available with the understanding that it will not be cited or reproduced without the permission of the author.

This report has been reproduced directly from the best available copy.

Available to DOE and DOE contractors from the

Office of Scientific and Technical Information

P.O. Box 62, Oak Ridge, TN 37831

Prices available from (423) 576-8401

http://apollo.osti.gov/bridge/

Available to the public from the

National Technical Information Service

U.S. Department of Commerce

5285 Port Royal Rd., Springfield, VA 22161

http://www.ntis.gov/

OR

Lawrence Livermore National Laboratory

Technical Information Department's Digital Library

http://www.llnl.gov/tid/Library.html 


\title{
Enhanced spin-valve giant magneto- resistance in non-exchange biased sand- wich films
}

\author{
M. Mao, C. Cerjan, B. Law and F. Grabner \\ Lawrence Livermore National Laboratory, P.O. Box 808, L-395, \\ Livermore, CA94550 \\ L. Miloslavsky and C. Chien \\ ReadRite Corporation, 44100 Osgood Rd., Fremont, CA94539
}

\begin{abstract}
A large giant magnetoresistance (GMR) value of $\mathbf{7 . 5 \%}$ has been measured in simple $\mathrm{NiFeCo}(1) / \mathrm{Cu} / \mathrm{NiFeCo}(2)$ sandwich films grown on a $30 \AA \mathrm{Cr}$ seed layer. This spin-valve GMR effect is consistent with the differential switching of the two NiFeCo layers due to an enhanced coercivity of the $\mathrm{NiFeCo}(1)$ layer grown on the $\mathrm{Cr}$ seed layer. A change in growth texture of the $\mathrm{NiFeCo(1)}$ layer from $f c c$ (111) to bcc (110) crystallographic orientation leads to an increase in magnetic anisotropy and and an enhancement in coercivity.

The GMR value increases to $8.7 \%$ when a thin CoFe interfacial enhancing layer is incorporated. Further enhancement in GMR values up to $14 \%$ is seen in the sandwich films by nanooxide layer formation. The specular reflection at oxide/magnetic layer interface further extends the mean free path of spinpolarized electrons.
\end{abstract}

Index terms-spin-valve, GMR, coercivity, specular reflection, seed layer, nano-oxide layer, sandwich.

\section{INTRODUCTION}

Spin-valve giant magnetoresistive (GMR) effect shows a great potential for application in magnetic random access memory (MRAM). Spin-valve effect is a result of differential switching of two weekly exchange coupled ferromagnetic $(F)$ layers across a non-magnetic spacer. In distinction to the conventional exchange biased spin-valve structure where one of the two $F$ layers is pinned by an antiferromagnetic layer, differential switching mechanism can also be created by designing the two $\mathrm{F}$ layers with different materials or different thicknesses [1,2]. The MRAM operation utilizing the second type spin-valve structure is conceptually simple [1,2]. A large read-out signal combined with a simple bit structure is always a desirable MRAM design point. We report in this paper the development of non-exchange biased $\mathrm{F} / \mathrm{Cu} / \mathrm{F}$ sandwich films with an enhanced GMR effect.

\section{EXPERIMENTAL METHODS}

$\mathrm{F}^{1} / \mathrm{Cu} / \mathrm{F}^{2}$ sandwich films, where $\mathrm{F}^{1}=\mathrm{NiFeCo}, \mathrm{NiFeCo} / \mathrm{CoFe}$, $\mathrm{CoFe}$, and $\mathrm{F}^{2}=\mathrm{NiFeCo}, \mathrm{CoFe} / \mathrm{NiFe}, \mathrm{CoFe} / \mathrm{NiFe} / \mathrm{CoFe}$, were

Manuscript received February 14, 2000.

Ming Mao, phone 925-422-7884;

Fax 925-422-9628; e-mail mao2@llnl.gov 
deposited on 4 in. Si substrates using a 6-target planetary DC magnetron sputtering system. A magnetic field of 50 Oe was present during film deposition to induce uniaxial anisotropy in the magnetic layers. A seed layer or a seed layer/nano-oxide composite layer was formed prior to the sandwich deposition, with varying thicknesses. A SHB-109 BH-loop tracer and a quasi-static tester were used for electric and magnetic characterization of the sheet films. The crystallographic properties and layered structure of the sandwich films were cvaluated using $\mathrm{x}$-ray diffraction and $\mathrm{x}$-ray reflectivity measurements.

\section{RESULTS AND DISCUSSION}

Symmetric $\mathrm{NiFeCo}(1) 40 \AA / \mathrm{Cu} 23 \AA / \mathrm{NiFeCo}(2) 40 \AA$ sandwich films only show anisotropic magnetoresistance. Large GMR values above $7 \%$ have been measured in the sandwich films once a proper seed layer is used. As shown in Fig. 1,
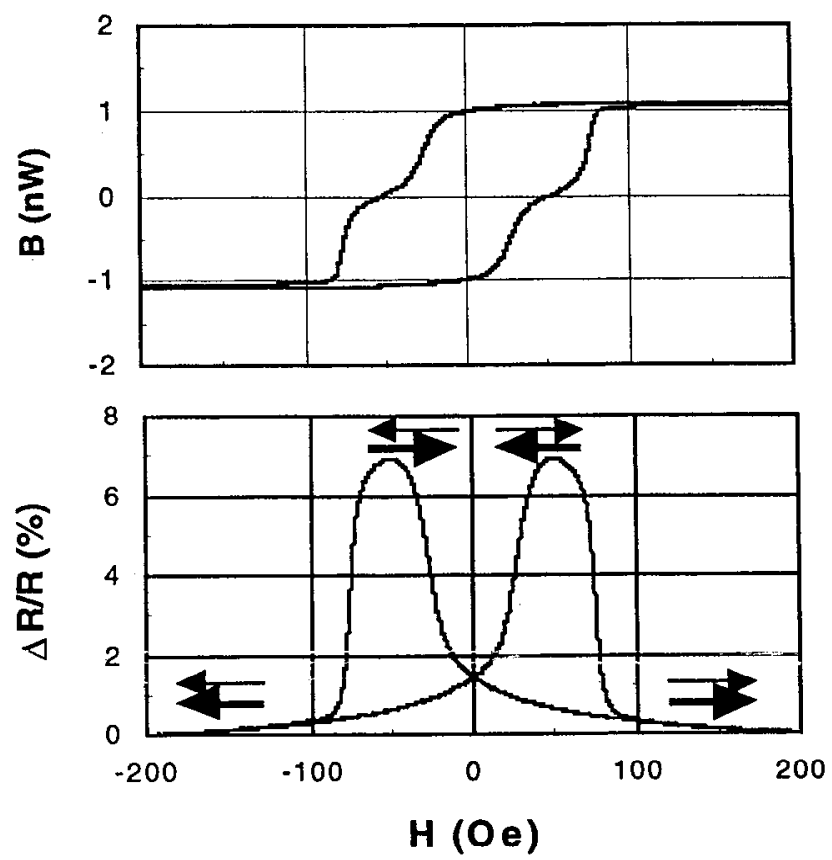

Fig. 1 Typical BH loop and GMR as a function of applied magnetic field for a $\mathrm{Cr} 30 \AA / \mathrm{NiFeCo} 40 \AA / \mathrm{Cu} 23 \AA / \mathrm{NiFeCo} 40 \AA$ sandwich film.

introducing a $\mathrm{Cr}$ seed layer leads to a difference in the switching fields between the two $\mathrm{NiFeCo}$ layers. $\mathrm{NiFeCo}(1)$ layer grown directly on the $\mathrm{Cr}$ seed layer exhibits a larger coercivity value, which prevents its magnetization from switching along with that of $\mathrm{NiFeCo}(2)$ layer. The occurrence of an antiparallel configuration of the magnetization between the two NiFeCo layers gives rise to the spin-valve GMR effect. 
Fig. 2 shows the dependence of coercivity for the two $\mathrm{NiFeCo}$ layers and GMR value on $\mathrm{Cr}$ seed layer thickness for $\mathrm{NiFeCo}(1) / \mathrm{Cu} / \mathrm{NiFeCo}(2)$ sandwich films. While the coercivity of $\mathrm{NiFeCo}(2)$ layer, $\mathrm{H}_{\mathrm{C} 2}$, remains almost unchanged

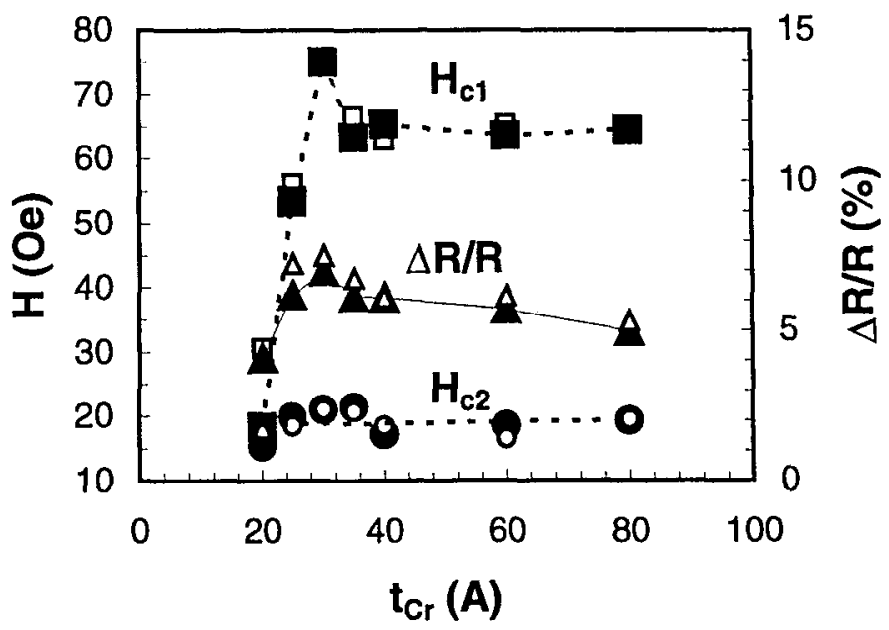

Fig. 2 Dependence of coercivity and $\triangle \mathrm{R} / \mathrm{R}$ on $\mathrm{Cr}$ seed layer thickness for $\mathrm{Cr}\left(\mathrm{t}_{\mathrm{Cr}}\right) / \mathrm{NiFeCo}(1) 40 \AA / \mathrm{Cu} 23 \AA / \mathrm{NiFeCo}(2) 40 \AA$ sandwich films. Close and open symbols represent data from as-deposited and annealed samples, respectively.

with increasing $\mathrm{Cr}$ layer thickness, the coercivity of $\mathrm{NiFeCo}(1)$ layer, $\mathrm{H}_{\mathrm{Cl}}$, increases quickly and reaches a plateau of $\sim 70$ Oe at $t_{C r} \geq 30 \AA$. This enhancement in $H_{C 1}$ is accompanied by a corresponding increase in GMR value. A large $\Delta R / R$ of $7 \%$ is observed at $t_{C r}=30 \AA$. The decrease in $\Delta R / R$ with further increasing $t_{C r}$ is due to the increasing current shunting through the seed layer. Annealing at $225 \mathrm{C}$ under an aligning magnetic field further improves GMR values to $7.5 \%$, as shown in Fig. 1 .

The enhancement in $\mathrm{H}_{\mathrm{Cl}}$ and $\Delta \mathrm{R} / \mathrm{R}$ in $\mathrm{NiFeCo}(1) / \mathrm{Cu} / \mathrm{NiFeCo}(2)$ sandwich films grown on $\mathrm{Cr}$ seed layer is associated with a change in growth texture of the $\mathrm{NiFeCo(1)}$ layer. X-ray diffraction measurements of these sandwich films confirm a significant change in the crystallugraphic orientation of the films with increasing $t_{\mathrm{Cr}}$. Two partly overlapping diffraction peaks at $2 \theta=43.9^{\circ}$ and $44.9^{\circ}$ have been identified to result from $f c c$ $\mathrm{NiFeCo} / \mathrm{Cu} / \mathrm{NiFeCo}(111)$ and $b c c \quad \mathrm{Cr}(110)$ diffractions, respectively. The pcaks arc very well described by Lorentzian line shape. The deconvoluted peak intensities are shown in Fig. 3(a) as a function of $t_{\mathrm{Cr}}$.

It is clear that while the $\operatorname{Cr}(110)$ diffraction peak is gradually enhanced with increasing $t_{C_{r}}$, the diffraction intensity of $\mathrm{NiFeCo} / \mathrm{Cu} / \mathrm{NiFeCo}(111)$ peak exhibits a significant initial decrease and it remains constant with further increasing $t_{c r} \geq 40 \AA$. Although the diffraction intensity of $\mathrm{NiFeCo} / \mathrm{Cu} / \mathrm{NiFeCo}(111)$ peak is contributed from three 


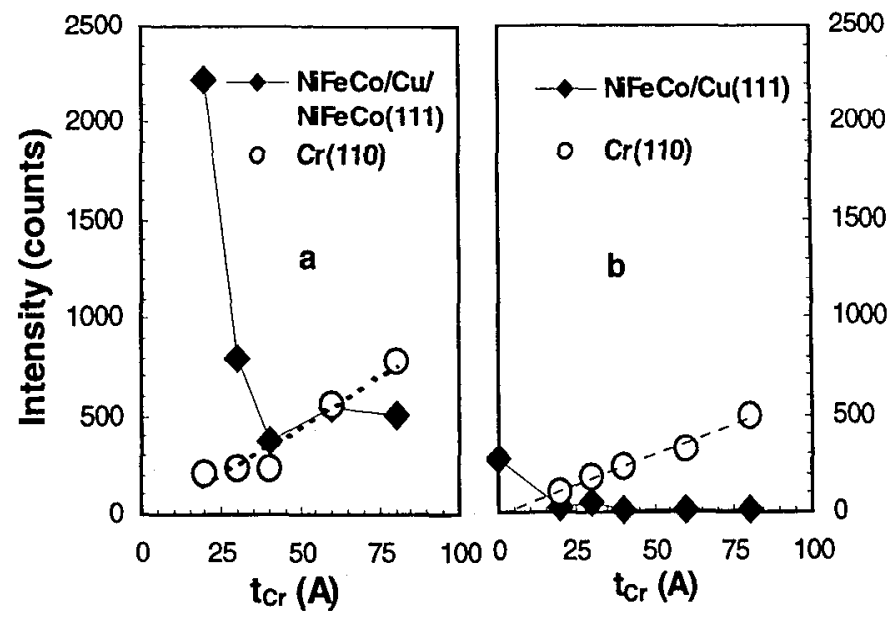

Fig. 3 X-ray diffraction peak intensity of (a) $\mathrm{NiFeCo(1)40 \AA /}$ $\mathrm{Cu} 23 \AA / \mathrm{NiFeCo}(2) 40 \AA$ sandwich with a $20 \AA \mathrm{Cr}$ capping layer and (b) $\mathrm{NiFeCo}(1) 40 \AA / \mathrm{Cu} 23 \AA$ bilayer films grown on a $\mathrm{Cr}$ seed layer with varying thickness.

consecutive component layers, the intensity decrease is a direct result of the change in the $f c c$ (111) texture of $\mathrm{NiFeCo}(1)$ layer grown on the $b c c \mathrm{Cr}$ seed layer. The nature of intra-grain epitaxial growth of multilayer thin films suggests that $\mathrm{NiFeCo}(1)$ layer grow into $b c c$ crystalline structure, resulting in an increase in the magnetocrystalline

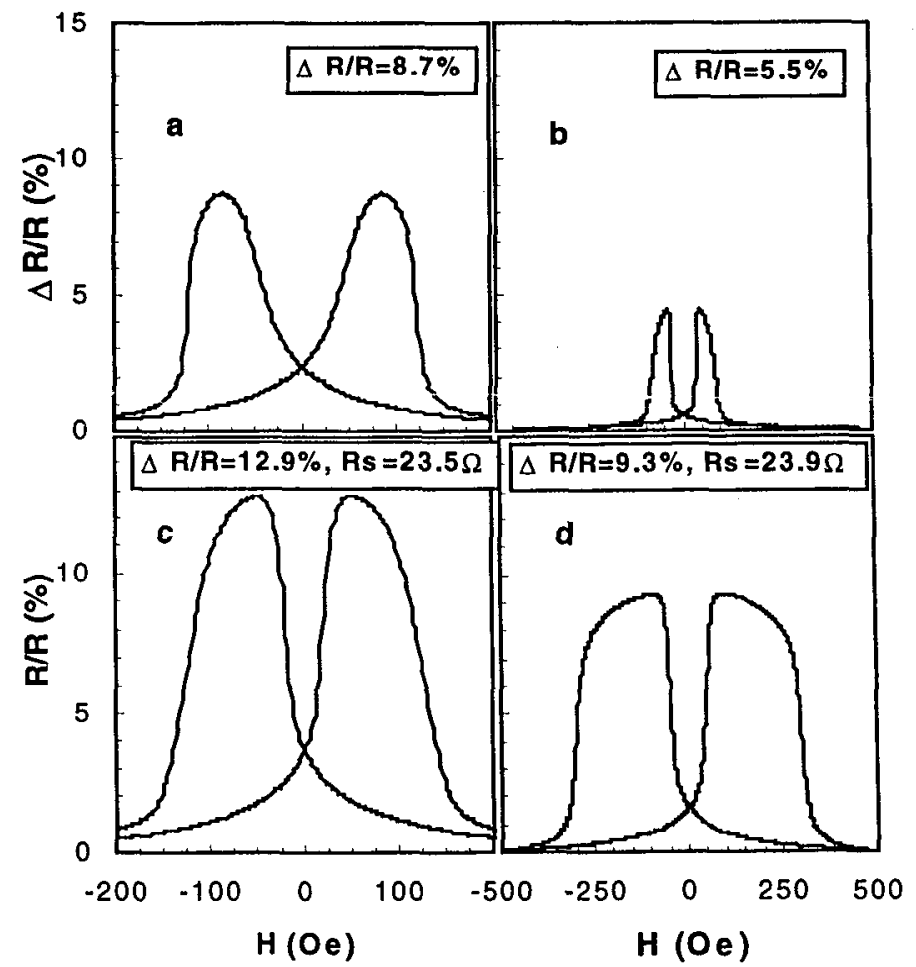

Fig. 4 Magnetoresistance as a function of applied magnetic field for four different sandwich films: (a) $\mathrm{Cr} 30 \AA / \mathrm{NiFeCo} 30 \AA / \mathrm{CoFe} 10 \AA$ $\mathrm{Cu} 23 \AA / \mathrm{CoFe} 10 \AA / \mathrm{NiFeCo} 30 \AA$, (b) $\mathrm{Ta} 20 \AA / \mathrm{CoFe} 40 \AA / \mathrm{Cu} 23 \AA$ $\mathrm{CoFe} 10 \AA / \mathrm{NiFeCo} 30 \AA / \mathrm{CoFe} 10 \AA / \mathrm{Ta} 4 \AA$, (c) $\mathrm{Cr} 30 \AA / \mathrm{CoFeO} / \mathrm{CoFe} 30 \AA /$ $\mathrm{Cu} 23 \AA / \mathrm{CoFc10} / \mathrm{NiFeC} 30 \AA / \mathrm{CoFc} 10 \AA \mathrm{Ta} 4 \AA$, (d) $\mathrm{CoFe} 40 \AA \mathrm{Cu} 23 \AA / \mathrm{CoFe} 10 \AA / \mathrm{NiFeCo} 30 \AA / \mathrm{CoFe} 10 \AA / \mathrm{Ta} 4 \AA$. 
anisotropy and therefore the coercivity. The suppression of fcc (111) texture in $\mathrm{NiFeCo}(1)$ layer with increasing $\mathrm{Cr}$ seed layer thickness is clearly demonstrated by the results of $\mathrm{x}$-ray diffraction measurements on $\mathrm{NiFeCo}(1) / \mathrm{Cu}$ bilayer films, as shown in Fig. 3(b). On the other hand, it also confirms that (111) crystallographic orientation is not a necessary condition to observe large GMR effect.

Our previous studies [3] on $[\mathrm{NiFeCo} / \mathrm{Cu}]_{20}$ and $[\mathrm{CoFe} / \mathrm{Cu}]_{20}$ multilayers have shown that these two multilayer systems show equivalent GMR values $20 \%$ at $20 \AA \mathrm{Cu}$ spacer layer thickness. The insertion of thin $\mathrm{CoFe}$ layers at $\mathrm{NiFeCo}$ and $\mathrm{Cu}$ interfaces, however, in the present $\mathrm{NiFeCo}(1) / \mathrm{Cu} / \mathrm{NiFeCo}(2)$ sandwich films enhances interfacial spin dependent scattering and further increases GMR values to $8.7 \%$, as shown in Fig. 4(a). A large GMR value of $9.3 \%$ has been measured [Fig. 4(d)] in the asymmetric sandwich films of structure $\mathrm{Cr} 30 \AA / \mathrm{CoFe} 40 \AA / \mathrm{Cu} 23 \AA / \mathrm{CoFe} 10 \AA / \mathrm{NiFe} 30 \AA / \mathrm{CoFe} 10 \AA 2 / \mathrm{Ta} 4 \AA$. This is in contrast to the sandwich film using a $20 \AA$ Ta seed layer [Fig. 4(b)] that exhibits a GMR value of only $5.5 \%$. A direct comparison of the Fig. 4(b) and (d) indicates that a larger difference in the switching fields between the two composite ferromagnetic layers for $\mathrm{Cr}$-seeded films ensures a well defined anti-parallel magnetization alignment and a large dynamical range to observe a large spin-valve GMR effect.

The large GMR value of the Cr-seeded asymmetric sandwich film may also result from specular enhancement of spin polarized electrons at the top surface due to the formation of a Ta oxide layer [4]. X-ray reflectivity measurements, as

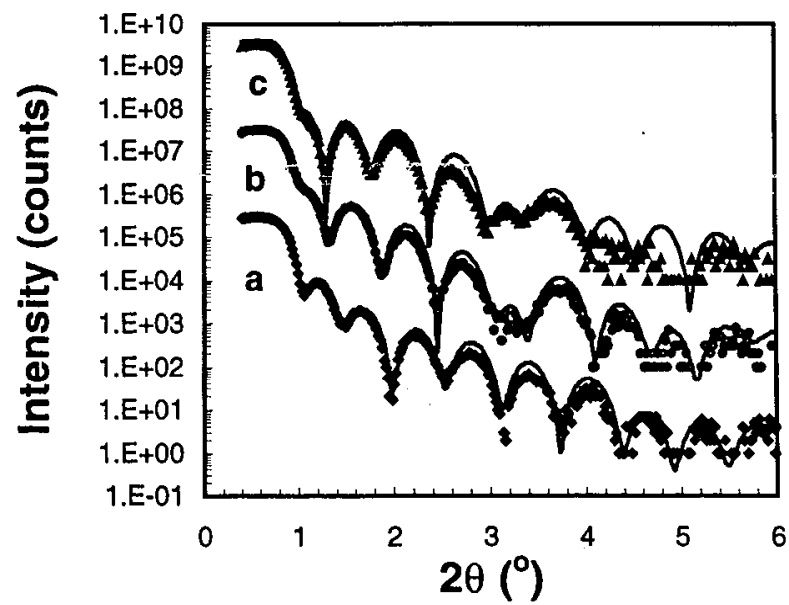

Fig. $5 \mathrm{X}$-ray reflectivity for three different sandwich films $\mathrm{Cr} 30 \AA / \mathrm{CoFe}\left(\mathrm{x}_{1}\right) \AA / \mathrm{CoFeO}\left(\mathrm{y}_{1}\right) \AA / \mathrm{CoFe} 30 \AA / \mathrm{Cu} 23 \AA / \mathrm{CoFe} 10 \AA$ $\mathrm{NiFe} 30 \AA / \mathrm{CoFe}\left(\mathrm{x}_{2}\right) \AA \AA / \mathrm{CoFeO}\left(\mathrm{y}_{2}\right) \AA ̊ / \mathrm{Ta} 4 \AA$; (a) $\mathrm{x}_{1}=\mathrm{x}_{2}=0$, $\mathrm{y}_{1} \approx \mathrm{y}_{2} \approx 18 \AA$; (b) $\mathrm{x}_{1}=\mathrm{y}_{2}=0, \mathrm{y}_{1} \approx 18 \AA, \mathrm{x}_{2}=10 \AA$; (c) $\mathrm{x}_{1}=\mathrm{x}_{2}=10 \AA$, $\mathrm{y}_{1}=\mathrm{y}_{2}=0$. The solid lines are the results from simple multilayer model analyses.

shown in Fig. 5, confirm that the $4 \AA$ Ta capping layer has been naturally oxidized into a $8 \AA \mathrm{TaO}_{x}$. Electron specular 
reflection at top $\mathrm{CoFe} / \mathrm{TaO}_{\mathrm{x}}$ interface could further extend the mean free path of spin polarized electrons.

The insertion of $\sim 18 \AA$ of $\mathrm{CoFeO}$ layer, estimated by the $\mathrm{x}$ ray reflectivity measurements, at $\mathrm{Cr} / \mathrm{CoFe}$ interface by oxidizing a $10 \AA \mathrm{CoFe}$ layer in pure $\mathrm{O}_{2}$ atmosphere further increases GMR value to $13 \%$, as shown in Fig. 4(c). This corroborates the specular enhancement of GMR cffect through specular reflection of electron at oxide/ferromagnetic layer interfaces $[4,5]$. The insertion of the $\mathrm{CoFe}$ nano-oxide layer at both sides of the sandwich films increases the GMR value only to $14 \%$, implying the role of naturally formed $\mathrm{TaO}_{x}$ at the top surface of the sandwich films. A $1.5 \%$ reduction in film sheet resistance is seen with the insertion of nano-oxide layers, as indicated by Table 1. An optimization of the individual component layer thicknesses and the oxidation condition is currently underway and is expected to further improve the GMR values.

Table 1 Summary of the GMR and sheet resistance values for three different sandwich films with or without nano-oxide layer insertion. a, b, c refer film structures specified in Fig. 5.

\begin{tabular}{|c|c|c|c|}
\hline & $\mathbf{a}$ & $\mathbf{b}$ & $\mathbf{C}$ \\
\hline insertion & none & one side & two sides \\
\hline$\Delta \mathbf{R} / \mathbf{R}(\%)$ & 9.3 & 12.9 & 13.9 \\
\hline $\mathbf{R s}(\Omega / \mathrm{sq})$ & 23.91 & 23.54 & 23.63 \\
\hline
\end{tabular}

\section{ConClusions}

Large GMR values up to $14 \%$ have been measured in nonexchange biased $F^{1} / \mathrm{Cu} / \mathrm{F}^{2}$ sandwich films. The enhancement in spin-valve GMR effect in $\mathrm{F}^{1} / \mathrm{Cu} / \mathrm{F}^{2}$ sandwich films grown on $\mathrm{Cr}$ seed layer is associated with an increase in magnetic anisotropy of the $\mathrm{F}^{1}$ layer resulting from a change in growth texture of the $F^{1}$ layer. Specular enhancement of electron reflection at F/nano-oxide interfaces can be used to further exploit the GMR effect in simple sandwich and exchange biased spin-valve films.

\section{REFERENCES}

[1] Z. Wang and Y. Nakamura, "Quaternary giant magnetoresistance random access memory" J. Appl. Phys. 79, 6639 (1996).

[2] B. A. Everitt, A. V. Pohm and J. M. Daughton, "Size dependence of switching thresholds for pseudo spin-valve MRAM cells" J. Appl. Phys. 81, 4020 (1997).

[3] M. Mao, (1997) unpublished.

[4] W. F. Egelhoff, Jr, P.J. Chen, C.J. Powell, M.D. Stiles, R.R. McMichael, J. H. Judy, K. Takano and A.E. Berkowitz, "Oxygen as surfactant in the growth of giant magnetoresistance spin valves", J. Appl. Phys. 82, 6142 (1997).

[5] H.J.M. Swagten, G.J. Strijkers, P.J.H. Bleomen, M.M.H. Willekens and W.J.M. de Jonge, " Enhanced giant magnetoresistance in spin-valves sandwiched between insulating NiO", 53, 9108 (1996).

Work performed under auspices of USDOE by UCLLNI, under contract No. W-7405-Eng-48. 